\title{
Solubilização do fosfato de ferro em meio de cultura
}

\author{
Cinthya Babá Barroso ${ }^{(1)}$ e Ely Nahas ${ }^{(2)}$
}

(1) In memoriam (2)Universidade Estadual Paulista, Faculdade de Ciências Agrárias e Veterinárias, Departamento de Produção Vegetal, Rodovia Prof. Paulo Donato Castellane, s/no, CEP 14884-900 Jaboticabal, SP. E-mail: enahas@fcav.unesp.br

\begin{abstract}
Resumo - O objetivo deste trabalho foi avaliar a eficiência de solubilização de $\mathrm{FePO}_{4}$ por Aspergillus niger, em meio de cultura com diferentes fontes de carbono $(\mathrm{C})$ e nitrogênio $(\mathrm{N})$ e com concentrações crescentes de fosfato. A quantidade de fosfato solúvel, acidez e pH final foram determinados após o crescimento do fungo, em cultura estacionária a $30^{\circ} \mathrm{C}$. A eficiência de solubilização aumentou conforme o crescimento do fungo, atingiu o máximo no $11^{\circ}$ dia $(68 \%)$ e depois regrediu. Das fontes de $\mathrm{C}$ e de $\mathrm{N}$ testadas, as maiores eficiências de solubilização foram obtidas com manitol (21\%) e ácido glutâmico (17\%). Com o aumento da concentração de fosfato (0 a

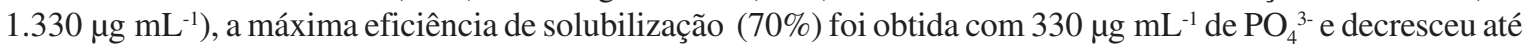
$47 \%$ com $1.330 \mu \mathrm{g} \mathrm{mL}^{-1}$. A produção de ácidos foi o principal mecanismo de solubilização do $\mathrm{FePO}_{4}$, com base na correlação positiva e significativa entre a produção de fosfato e a acidez.
\end{abstract}

Termos para indexação: Aspergillus niger, acidez titulável, fontes de carbono, fontes de nitrogênio, fosfato solúvel.

\section{Solubilization of hardly soluble iron phosphate in culture medium}

\begin{abstract}
The objective of this work was to evaluate the efficiency of solubilization of $\mathrm{FePO}_{4}$ by Aspergillus niger, in culture medium with different carbon $(\mathrm{C})$ and nitrogen $(\mathrm{N})$ sources, and enhancing concentrations of phosphate. The amount of soluble phosphate, acidity and final $\mathrm{pH}$ were determined after the fungus growth in a stationary culture at $30^{\circ} \mathrm{C}$. Efficiency of solubilization increased according to fungus growth, reaching the maximum at the $11^{\text {th }}$ day $(68 \%)$ and later decreased. In relation to $\mathrm{C}$ and $\mathrm{N}$ sources, the largest efficiencies of solubilization were found with mannitol (21\%) and glutamic acid (17\%). Increasing phosphate concentration ( 0 to $1,330 \mu \mathrm{g} \mathrm{mL} L^{-1}$ ), maximal efficiency of solubilization $(70 \%)$ was found with $330 \mu \mathrm{g} \mathrm{mL} L^{-1} \mathrm{PO}_{4}{ }^{3-}$, and decreased up to $47 \%$ with $1,330 \mu \mathrm{g} \mathrm{mL}{ }^{-1} \mathrm{PO}_{4}{ }^{3-}$. The amount of acids produced was the factor that more influenced $\mathrm{FePO}_{4}$ solubilization, based in the positive and significant correlation between phosphate and acidity production.
\end{abstract}

Index terms: Aspergillus niger, titratable acidity, carbon sources, nitrogen sources, soluble phosphate.

\section{Introdução}

O fósforo (P) é um nutriente essencial para o crescimento e desenvolvimento das plantas, por seu papel em biomoléculas importantes como ácidos nucléicos (DNA, RNA e outros), fosfolipídios e nucleotídios (ATP, GTP e outros). A planta adquire fosfato da solução do solo, predominantemente nas formas $\mathrm{HPO}_{4}{ }^{2-}$, quando em $\mathrm{pH}$ menor que $7,2, \mathrm{e}_{2} \mathrm{PO}_{4}{ }^{-}$quando em $\mathrm{pH}$ maior que 7,2 (Wakelin et al., 2004). No entanto, a quantidade de ortofosfato existente na solução do solo é menor que $1 \%$ do P total (Mullen, 2005). Assim, apesar da ampla distribuição de $\mathrm{P}$ na natureza, a sua deficiência é comum por causa da forma altamente insolúvel encontrada, principalmente, em solos ácidos de regiões tropicais e subtropicais com alta potencialidade de produção, o que resulta em baixa disponibilidade para as plantas (Zapata \& Axmann, 1995). Além disso, o P em solução pode ser adsorvido na superfície dos minerais de argila, em solos neutros ou alcalinos, ou na superfície de óxidos de ferro e de alumínio e minerais de argila em solos ácidos.

Microrganismos do solo, inclusive bactérias e fungos, solubilizam formas inorgânicas não disponíveis de $\mathrm{P}$ (Xin et al., 2002; Son et al., 2006). Esses microrganismos utilizam estratégias bioquímicas, como a produção de ácidos orgânicos, ou um mecanismo que envolve o crescimento microbiano e que favorece a secreção de prótons $\left(\mathrm{H}^{+}\right)$(Illmer et al., 1995).

Fungos filamentosos têm sido amplamente usados como produtores de ácidos e, em particular, espécies de Aspergillus e de Penicillium mostraram habilidade de solubilizar diferentes formas de fosfatos de cálcio 
(Vassilev et al., 1996; Narsian \& Patel, 2000). Porém, os solos das áreas agrícolas do Brasil geralmente apresentam condição ácida e predomínio de fosfato de ferro. De acordo com Barroso \& Nahas (2005), entre as frações de fósforo encontradas em solos sob pasto, floresta, mata e cultura de milho a mais abundante foi a de fosfato de ferro (Fe-P), seguida de fosfato de alumínio (Al-P) e fosfato de cálcio (Ca-P). A solubilidade destes fosfatos é muito baixa e decresce na seguinte ordem: $\mathrm{Ca}-\mathrm{P}>\mathrm{Al}-\mathrm{P}>\mathrm{Fe}-\mathrm{P}$.

Há poucos estudos que abordaram a solubilização do $\mathrm{FePO}_{4}$, e os resultados não foram tão satisfatórios quando comparados com outros fosfatos. Por exemplo, a solubilização de hidroxiapatita por $P$. rugulosum foi mais eficiente do que a dos fosfatos de ferro ou alumínio (Reyes et al., 1999). Similarmente, estes fosfatos foram pouco solubilizados quando comparados com hidroxiapatita, $\mathrm{CaHPO}_{4} \mathrm{e} \mathrm{Ca}_{3}\left(\mathrm{PO}_{4}\right)_{2}$ (Son et al., 2006). Fungos micorrízicos solubilizaram $\mathrm{CaHPO}_{4}$, mas não fosfatos de ferro ou de alumínio (Gibson \& Mitchell, 2004).

Entre os fungos, $A$. niger tem sido bastante estudado por sua habilidade de produzir ácidos orgânicos, principalmente o ácido cítrico (Bizukojc \& Ledakowicz, 2004). Inúmeros mecanismos têm sido propostos, com relação à sua regulação e síntese, e a produção deste ácido é influenciada pelo $\mathrm{pH}$ do meio, as fontes de carbono (C), nitrogênio (N), $\mathrm{P}$ e micronutrientes (Papagianni et al., 2005). Em conseqüência dessa habilidade, a influência de diferentes fatores na capacidade e potencial de solubilização de diferentes fosfatos por este fungo foi estudada (Reyes et al., 1999; Silva Filho \& Vidor, 2000).

Considerando-se que um isolado de solo A. niger mostrou alta habilidade de solubilizar fosfato de ferro em meio de cultura (Barroso \& Nahas, 2005), este estudo teve por objetivo averiguar a eficiência de solubilização do $\mathrm{FePO}_{4}$, pelo fungo em meio de cultura, tendo-se variado as fontes de carbono e de nitrogênio e a concentração de fosfato.

\section{Material e Métodos}

O fungo Aspergillus niger F111 foi isolado de um Nitossolo Vermelho e encontra-se estocado no Laboratório de Microbiologia (Barroso \& Nahas, 2005). O fungo cresceu em meio inclinado de Sabouraud, por oito dias a $30^{\circ} \mathrm{C}$. Subculturas foram feitas a cada 30 dias.
O inóculo foi preparado a partir de dois tubos com o fungo, aos quais se adicionou água destilada e esterilizada. Os esporos foram transferidos para um tubo e filtrados em funil com gaze esterilizada. O número de esporos foi determinado em câmara de Newbauer. Foram inoculados $2 \mathrm{~mL}$ da suspensão com $13 \times 10^{6}$ esporos $\mathrm{mL}^{-1}$, em $30 \mathrm{~mL}$ de meio de cultura contido em frascos Erlenmeyer de $250 \mathrm{~mL}$.

$\mathrm{O}$ fungo cresceu em meio líquido $\mathrm{MS}$, com $\mathrm{pH}$ 7, que continha, por litro: $0,1 \mathrm{~g}$ de $\mathrm{NaCl}, 1 \mathrm{~g}$ de $\mathrm{NH}_{4} \mathrm{Cl}, 0,2 \mathrm{~g}$ de $\mathrm{KCl}, 0,1 \mathrm{~g}$ de $\mathrm{CaCl}_{2} \cdot 2 \mathrm{H}_{2} \mathrm{O}, 1,2 \mathrm{~g}$ de $\mathrm{MgSO}_{4} \cdot 7 \mathrm{H}_{2} \mathrm{O}, 10 \mathrm{~g}$ de glicose, 0,5 g de extrato de levedura (Nahas et al., 1994). $\mathrm{FePO}_{4}$ foi adicionado na quantidade de $1,26 \mathrm{~g} \mathrm{~L}^{-1}$ de $\mathrm{PO}_{4}{ }^{3-}$.

Quando se avaliou o efeito da fonte de C sobre a solubilização de $\mathrm{FePO}_{4}$, arabinose, xilose, frutose, galactose, manose, maltose, sacarose, amido solúvel ou manitol, foram adicionados $\left(4 \mathrm{~g} \mathrm{~L}^{-1} \mathrm{de} \mathrm{C}\right)$ ao meio MS. Cada solução com a fonte de carbono foi esterilizada separadamente, por filtração, e adicionada ao meio de cultura antes da inoculação. O efeito da fonte de $\mathrm{N}$ na solubilização foi avaliado, tendo-se substituído o cloreto de amônio por: nitrato de amônio, sulfato de amônio, nitrato de sódio, nitrato de potássio, glicina, ácido glutâmico ou uréia, em quantidades de $262 \mathrm{mg} \mathrm{L}^{-1}$ de N. A fonte de $\mathrm{C}$ utilizada foi sacarose. $\mathrm{O}$ efeito da fonte de $\mathrm{P}$ foi determinado com concentrações crescentes de $\mathrm{FePO}_{4}$ p.a. no meio de cultura, de 0 a $1.330 \mu \mathrm{g} \mathrm{mL}^{-1}$ de $\mathrm{PO}_{4}{ }^{3-}$. As fontes de $\mathrm{Ce} \mathrm{N}$ utilizadas foram manitol e ácido glutâmico, nas concentrações de $4 \mathrm{~g} \mathrm{~L}^{-1}$ de Ce $262 \mathrm{mg} \mathrm{L}^{-1}$ de $\mathrm{N}$, respectivamente.

O crescimento do fungo A. niger foi avaliado em meio MS, por um período de 1 a 17 dias, tendo-se empregado manitol e ácido glutâmico nas concentrações de $4 \mathrm{~g} \mathrm{~L}^{-1}$ de $\mathrm{C}$ e $262 \mathrm{mg} \mathrm{L}^{-1} \mathrm{de} \mathrm{N}$, respectivamente, como fontes de $\mathrm{C}$ e de $\mathrm{N}$.

Quando não especificadas as condições do ensaio, o fungo foi incubado, sem agitação, à temperatura de $30^{\circ} \mathrm{C}$ durante oito dias. Ao final do período de incubação, o meio de cultura foi filtrado em funil de Buchner com papel de filtro Whatman no 1 , previamente secado a $105^{\circ} \mathrm{C}$ por 24 horas, e o micélio foi lavado com uma solução de $\mathrm{HCl}$ 0,5 M e água destilada. Determinou-se a biomassa micelial secada em estufa a $105^{\circ} \mathrm{C}$ por 24 horas.

No filtrado, foram determinados o fosfato solúvel pelo método de Ames (1966), o pH e a acidez, titulando-se, em titulador automático, uma alíquota de $10 \mathrm{~mL}$ do filtrado, com solução-padrão de $\mathrm{NaOH}$ 0,02 M até pH 7 . 
A atividade de solubilização correspondeu à quantidade de fosfato produzida no meio de cultura pelo fungo. A eficiência de solubilização do $\mathrm{FePO}_{4}$, em percentagem, foi determinada, tendo-se relacionado as médias correspondentes às quantidades de fosfato solubilizadas com as adicionadas ao meio de cultura.

Os dados foram submetidos à análise estatística, e as médias de três repetições foram comparadas pelo teste de Tukey, a 5\% de probabilidade, com o programa SAS. Foi, também, estimada a relação entre as variáveis, pelo coeficiente de correlação de Pearson.

\section{Resultados e Discussão}

A solubilização de fosfatos inorgânicos tem sido atribuída a inúmeros mecanismos, muitas vezes interdependentes, como o crescimento do fungo, a produção de ácidos e a diminuição do pH. Neste trabalho, o efeito de diferentes fontes de $\mathrm{C}$ e de $\mathrm{N}$, de concentrações de fosfato e do crescimento fúngico foram averiguados nesses mecanismos. A relação entre essas variáveis foi avaliada pelo coeficiente de correlação (Tabela 1). Os resultados da correlação dos

Tabela 1. Coeficientes de correlação entre as quantidades de fosfato solúvel, acidez titulável, biomassa micelial seca do micélio e $\mathrm{pH}$ final do meio de cultura ${ }^{(1)}$.

\begin{tabular}{lcccr}
\hline Variáveis & $\mathrm{C}$ & $\mathrm{N}$ & $\mathrm{P}$ & Fungo \\
\hline Micélio x acidez & $0,174^{\mathrm{ns}}$ & $0,019^{\mathrm{ns}}$ & $0,614^{* *}$ & $0,821^{* *}$ \\
Micélio x pH & $0,716^{* *}$ & $0,606^{* *}$ & $-0,292^{\mathrm{ns}}$ & $-0,787^{* *}$ \\
Acidez x pH & $-0,617^{* *}$ & $-0,621^{* *}$ & $-0,071^{\mathrm{ns}}$ & $-0,823^{* *}$ \\
Fosfato x micélio & $-0,504^{* *}$ & $0,646^{* *}$ & $0,676^{* *}$ & $0,789^{* *}$ \\
Fosfato x acidez & $0,705^{* *}$ & $0,579^{* *}$ & $0,948^{* *}$ & $0,970^{* *}$ \\
Fosfato x pH & $-0,023^{\text {ns }}$ & $0,212^{\text {ns }}$ & $0,068^{\text {ns }}$ & $-0,802^{* *}$
\end{tabular}

(1) Micélio ( $\left.\mathrm{mg} \mathrm{mL}^{-1}\right)$; acidez titulável $\left(\mathrm{mg} \mathrm{mL}^{-1}\right.$ de $\left.\mathrm{NaOH}\right)$; fosfato solúvel ( $\mu \mathrm{g} \mathrm{mL} \mathrm{m}^{-1}$ de $\mathrm{PO}_{4}^{-3}$ ); $\mathrm{C}$, efeito das fontes de carbono; $\mathrm{N}$, efeito das fontes de nitrogênio; $\mathrm{P}$, efeito de concentrações crescentes de fosfato

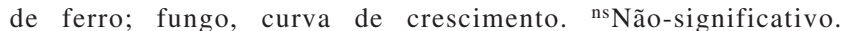
**Significativo a $1 \%$ de probabilidade. vários ensaios estudados podem dar indícios importantes sobre o mecanismo e a eficiência de solubilização (ES) do $\mathrm{FePO}_{4}$ por $A$. niger no ambiente.

A atividade de solubilização foi relacionada ao tipo de carboidrato testado e, a mais alta ES foi verificada em meio adicionado de manitol (Tabela 2). Os outros carboidratos induziram a solubilização, mas a quantidade de fosfato solubilizada foi menor que a obtida com manitol. Todas as fontes de carbono foram assimiladas por A. niger, porém proporcionaram diferentes respostas. Com glicose, o crescimento $\left(7,34 \mathrm{mg} \mathrm{mL}^{-1}\right)$ foi bastante estimulado, quando se comparou com outros carboidratos, mas houve redução acentuada da quantidade de fosfato produzida $(\mathrm{ES}<1 \%)$. Contrariamente, manitol foi uma das fontes de carbono que menos estimularam o crescimento fúngico (3,61 $\left.\mathrm{mg} \mathrm{mL}^{-1}\right)$, porém a solubilização foi bastante ativada, com ES máxima de $21 \%$.

Não foi detectada diferença entre o $\mathrm{pH}$ final da cultura com manitol, glicose, galactose, frutose e xilose (Tabela 2). A diminuição de $\mathrm{pH}$ pode ser atribuída à absorção de carboidrato e $\mathrm{NH}_{4}{ }^{+}$durante o crescimento fúngico. Manitol e galactose foram as fontes de $\mathrm{C}$ que proporcionaram maior produção de ácidos e também maior ES. Diferentemente, esses açúcares induziram a produção de pouco ácido cítrico, quando comparados com os demais utilizados no presente estudo (Xu et al., 1989). Possivelmente, diferentes condições do ensaio ocasionaram variadas respostas ou o ácido cítrico não foi o agente predominante na solubilização do $\mathrm{FePO}_{4}$, nas condições do presente estudo.

A variação observada na atividade de solubilização pode refletir uma variada exigência do carboidrato pelo fungo, como também do mecanismo de solubilização. O mecanismo de solubilização foi relacionado, na literatura, à produção de ácidos e à consequiente

Tabela 2. Eficiência de solubilização do fosfato de ferro por Aspergillus niger, em meio de cultura suplementado com diferentes fontes de carbono ${ }^{(1)}$.

\begin{tabular}{|c|c|c|c|c|c|}
\hline $\begin{array}{l}\text { Fonte } \\
\text { de carbono }\end{array}$ & $\begin{array}{l}\text { Micélio } \\
\left(\mathrm{mg} \mathrm{mL}^{-1}\right)\end{array}$ & $\begin{array}{c}\text { Acidez titulável } \\
\left(\mu \mathrm{g} \mathrm{mL}^{-1} \text { de } \mathrm{NaOH}\right)\end{array}$ & $\begin{array}{c}\mathrm{pH} \\
\text { final }\end{array}$ & $\begin{array}{c}\text { Fosfato solúvel } \\
\left(\mu \mathrm{g} \mathrm{mL}^{-1} \text { de } \mathrm{PO}_{4}^{-3}\right)\end{array}$ & $\begin{array}{c}\text { Eficiência de } \\
\text { solubilização (\%) }\end{array}$ \\
\hline Arabinose & $2,77 f$ & $108 \mathrm{~h}$ & $3,88 \mathrm{a}$ & $64,75 \mathrm{e}$ & 5,14 \\
\hline Xilose & $6,22 \mathrm{c}$ & $354 f$ & $2,22 \mathrm{dc}$ & $23,13 \mathrm{~h}$ & 1,84 \\
\hline Frutose & $6,49 \mathrm{cb}$ & $393 d$ & $2,22 \mathrm{dc}$ & $37,08 \mathrm{f}$ & 2,94 \\
\hline Galactose & $7,55 \mathrm{a}$ & $685 a$ & $2,20 \mathrm{~cd}$ & $132,22 b$ & 10,49 \\
\hline Glicose & $7,34 \mathrm{a}$ & $323 \mathrm{~g}$ & $2,21 \mathrm{dc}$ & $8,55 \mathrm{j}$ & 0,68 \\
\hline Manose & $5,34 d$ & $531 \mathrm{c}$ & $2,29 b$ & $91,26 \mathrm{c}$ & 7,24 \\
\hline Maltose & $6,66 \mathrm{~b}$ & $370 \mathrm{e}$ & $2,20 \mathrm{~d}$ & $30,53 \mathrm{~g}$ & 2,42 \\
\hline Sacarose & $7,37 \mathrm{a}$ & $323 \mathrm{~g}$ & $2,19 \mathrm{~d}$ & $18,04 \mathrm{i}$ & 1,43 \\
\hline Amido & $6,16 \mathrm{c}$ & $370 \mathrm{e}$ & $2,34 b$ & $83,71 \mathrm{~d}$ & 6,64 \\
\hline Manitol & $3,61 \mathrm{e}$ & $662 b$ & $2,24 \mathrm{c}$ & $261,18 \mathrm{a}$ & 20,73 \\
\hline
\end{tabular}

${ }^{(1)}$ Médias seguidas por letras iguais, na coluna, não diferem entre si pelo teste de Tukey, a 5\% de probabilidade. 
diminuição do pH (Vassilev et al., 2006; Chuang et al., 2007). Efetivamente, foi observada relação significativa entre a solubilização e a produção de ácidos $\left(\mathrm{R}^{2}=0,705^{* *}\right)$, mas não com a diminuição do $\mathrm{pH}$ $\left(R^{2}=-0,023^{\text {ns }}\right.$, Tabela 1$)$. O efeito da acidez titulável, na solubilização do $\mathrm{FePO}_{4}$, está de acordo com as observações de Chuang et al. (2007) com A. niger. A Tabela 1 mostra, também, uma correlação significativa e negativa entre a produção de fosfato e a de micélio $\left(\mathrm{R}^{2}=-0,504 * *\right)$. Com base nesse resultado, pode-se sugerir, também, que a alta solubilização em meio com manitol pode ocorrer em razão da baixa produção de micélio, o que acarreta, por conseguinte, menor captação de fosfato solúvel pelo fungo para seu crescimento. Similarmente, Xu et al. (1989) relataram que manitol foi uma das fontes de $\mathrm{C}$ que proporcionou reduzido crescimento ao fungo.

Máximo crescimento e produção de fosfato foram obtidos em culturas com ácido glutâmico, em comparação com as outras fontes de $\mathrm{N}$ (Tabela 3). Culturas com ácido glutâmico proporcionaram a máxima ES (17\%) do $\mathrm{FePO}_{4}$. Porém, a maior acidez titulável e o menor valor de $\mathrm{pH}$ foram observados em meio adicionado de sulfato de amônio. É possível que o glutamato seja consumido como substrato respiratório e canalizado, posteriormente, pelo ciclo dos ácidos tricarboxílicos (Chalot et al., 1994). A absorção de $\mathrm{NH}_{4}{ }^{+}$de compostos como o sulfato de amônio, com a liberação de $\mathrm{H}^{+}$ causando solubilização, tem sido atribuída à manutenção do equilíbrio iônico na célula (Illmer et al., 1995). Segundo Papagianni et al. (2005), $\mathrm{NH}_{4}{ }^{+}$participaria de um "pool", que levaria à inibição da enzima fosfofrutoquinase, com conseqüente ativação da glicólise e produção de ácido cítrico, durante os estágios iniciais da fermentação.

A atividade de solubilização, nas culturas que cresceram com ácido glutâmico, foi de 1,6 a 10 vezes maior do que com as outras fontes de N. A solubilização de fosfatos inorgânicos tem sido atribuída principalmente à produção de ácido cítrico por $A$. niger (Vassilev et al. 2006). Porém, de acordo com Kumar et al. (2000), embora o glutamato seja absorvido por A. niger, pode não ter influência significativa na produção de ácido cítrico. Portanto, o efeito de solubilização, em consequiência do ácido glutâmico, pode ser decorrente de outro mecanismo que inclui a produção de outros ácidos orgânicos como glicólico, glucônico, oxálico e succínico (Sperber, 1958; Roukas, 2000; Rymowicz \& Lenart, 2003). De fato, o ácido oxálico foi predominante na solubilização de fosfato de ferro ou de alumínio por A. niger, e o ácido glucônico na solubilização de fosfato de cálcio (Chuang et al., 2007).

Com base nos resultados obtidos (Tabelas 2 e 3), os ensaios seguintes foram conduzidos com manitol e ácido glutâmico como fontes de $\mathrm{C}$ e $\mathrm{N}$, respectivamente. A influência do crescimento do fungo A. niger na solubilização de fosfato de ferro foi avaliada no período de 1 a 17 dias. Foi observada uma fase de crescimento lento do fungo, que perdurou aproximadamente até o oitavo dia de incubação, seguida de uma fase de crescimento rápido, em que a biomassa micelial aumentou consideravelmente com o tempo (Figura $1 \mathrm{~A}$ ). O desenvolvimento do fungo alcançou o máximo no décimo dia de incubação e foi constante até o 11o dia, quando a biomassa seca diminuiu. $\mathrm{O}$ pH do meio decresceu de um valor inicial 6 para 1,6, no nono dia de incubação, e isto pode ter inibido o crescimento fúngico (Figura 1 B). Esta significativa diminuição do $\mathrm{pH}$ ocorreu em razão do consumo do açúcar por A. niger, que resultou na produção de ácidos orgânicos (Yuan et al., 2005). Presume-se que a diminuição nos valores de $\mathrm{pH}$ esteja associada ao aumento da acidez no meio, durante o crescimento inicial do fungo (até o oitavo dia)

Tabela 3. Eficiência de solubilização do fosfato de ferro por Aspergillus niger, em meio de cultura suplementado com diferentes fontes de nitrogênio ${ }^{(1)}$.

\begin{tabular}{|c|c|c|c|c|c|}
\hline $\begin{array}{l}\text { Fonte de } \\
\text { nitrogênio }\end{array}$ & $\begin{array}{l}\text { Micélio } \\
\left(\mathrm{mg} \mathrm{mL}^{-1}\right)\end{array}$ & $\begin{array}{c}\text { Acidez titulável } \\
\left(\mu \mathrm{g} \mathrm{mL} \mathrm{mL}^{-1} \text { de } \mathrm{NaOH}\right)\end{array}$ & $\begin{array}{c}\mathrm{pH} \\
\text { final }\end{array}$ & $\begin{array}{c}\text { Fosfato solúvel } \\
\left(\mu \mathrm{g} \mathrm{mL}^{-1} \text { de } \mathrm{PO}_{4}^{-3}\right)\end{array}$ & $\begin{array}{c}\text { Eficiência de solubilização } \\
(\%)\end{array}$ \\
\hline Cloreto de amônio & $5,64 \mathrm{e}$ & $356 \mathrm{c}$ & $2,38 f$ & $32,45 \mathrm{f}$ & 2,58 \\
\hline Nitrato de amônio & $5,86 \mathrm{e}$ & $116 \mathrm{e}$ & $3,89 \mathrm{~d}$ & $53,18 \mathrm{e}$ & 4,22 \\
\hline Sulfato de amônio & $5,71 \mathrm{e}$ & $643 a$ & $2,62 \mathrm{e}$ & $129,43 b$ & 10,27 \\
\hline Nitrato de potássio & $6,31 d$ & $147 d$ & $5,55 a$ & $89,82 d$ & 7,13 \\
\hline Nitrato de sódio & $6,85 \mathrm{c}$ & $156 \mathrm{~d}$ & $5,52 \mathrm{a}$ & $103,51 \mathrm{c}$ & 8,21 \\
\hline Glicina & $7,17 \mathrm{~b}$ & $141 \mathrm{ed}$ & $5,05 \mathrm{c}$ & $46,97 \mathrm{e}$ & 3,73 \\
\hline Ácido glutâmico & $9,56 \mathrm{a}$ & $410 \mathrm{~b}$ & $5,33 b$ & $212,80 \mathrm{a}$ & 16,89 \\
\hline Uréia & $6,74 \mathrm{c}$ & $32 \mathrm{f}$ & $5,05 \mathrm{c}$ & $21,22 \mathrm{~g}$ & 1,68 \\
\hline
\end{tabular}

${ }^{(1)}$ Médias seguidas por letras iguais, na coluna, não diferem entre si pelo teste de Tukey, a 5\% de probabilidade. 
(Figura 1 B). Pode-se notar que, após o 12o dia, a acidez diminuiu, e o $\mathrm{pH}$ aumentou. A produção de fosfato (Figura 1 A) e de ácidos (Figura 1 B) seguiu uma curva semelhante à do crescimento do fungo. A relação da produção de micélio com as quantidades de fosfato solúvel $\left(\mathrm{R}^{2}=0,789^{* *}\right)$ e as de ácidos $\left(\mathrm{R}^{2}=0,821^{* *}\right)$, observada na Tabela 1 , mostrou correlação altamente significativa e positiva. Assim, provavelmente, a solubilização do $\mathrm{FePO}_{4}$ pode ser relacionada ao crescimento do fungo e à produção de ácidos. A produção de ácidos foi máxima no 11 dia, assim como a ES do $\mathrm{FePO}_{4}(68 \%$,
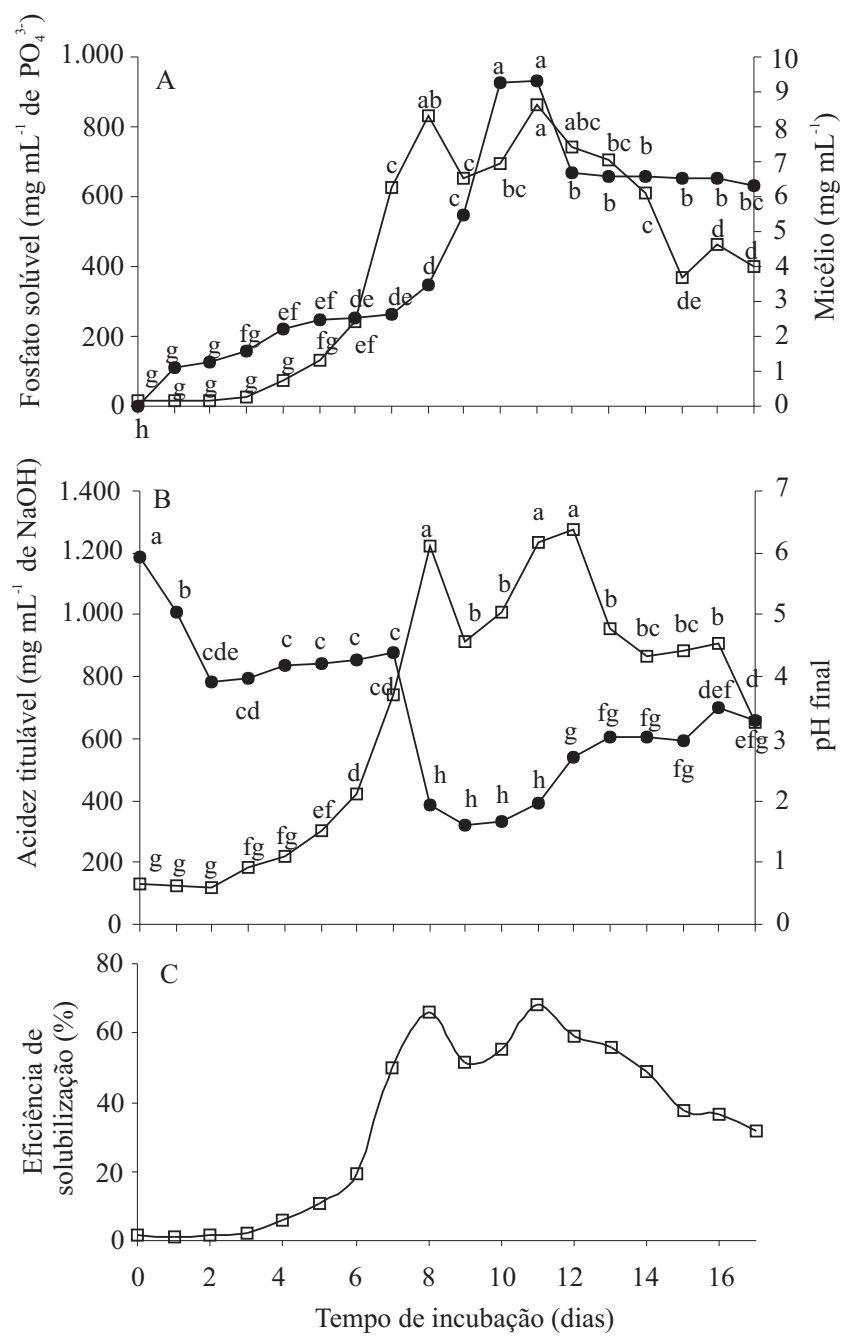

Figura 1. Crescimento do fungo Aspergillus niger e eficiência de solubilização do fosfato de ferro. Médias com letras iguais não diferem entre si pelo teste de Tukey, a 5\% de probabilidade. fosfato solúvel e acidez titulável. $\square$ : $\mathrm{pH}$ final e micélio.
Figura $1 \mathrm{C}$ ), e diminuiu significativamente após o 13으 dia. Provavelmente, a diminuição da acidez e do crescimento do fungo e o aumento do $\mathrm{pH}$ influíram na diminuição da ES.

Os resultados do crescimento do fungo, em meio de cultura com concentrações crescentes de $\mathrm{PO}_{4}{ }^{3-}$ (0 a $1.330 \mu \mathrm{g} \mathrm{mL}^{-1}$ ), foram reunidos na Figura 2. Em relação à concentração zero, significativo aumento da acidez e da atividade de solubilização foi constatado, quando as concentrações de $\mathrm{PO}_{4}{ }^{3-}$ do meio de cultura foram aumentadas para 665 e $330 \mu \mathrm{g} \mathrm{mL}^{-1}$ (Figura $2 \mathrm{~A}$ e B, respectivamente). Embora tenha sido verificada correlação significativa e positiva (Tabela 1) da concentração de fosfato com a acidez $\left(\mathrm{R}^{2}=0,948^{* *}\right)$ e com a biomassa micelial seca $\left(\mathrm{R}^{2}=0,676^{* *}\right)$, e da acidez com o peso de micélio $\left(\mathrm{R}^{2}=0,614^{* *}\right)$, a ES diminuiu de 70 para $47 \%$ (Figura $2 \mathrm{C}$ ), respectivamente, quando a concentração de fosfato da cultura aumentou de 330 a $1.330 \mu \mathrm{g} \mathrm{mL}^{-1}$. Algumas razões podem ser consideradas para esta resposta. Embora a quantidade de fosfato tenha aumentado significativamente o crescimento do fungo, a produção de ácidos e a diminuição do pH não corresponderam a esse aumento. Similarmente ao presente trabalho, o crescimento do fungo A. niger foi limitado a concentrações acima de $100 \mu \mathrm{g} \mathrm{mL}^{-1}$ de $\mathrm{K}_{2} \mathrm{HPO}_{4}$ (Komano, 1975). Outro efeito que pode explicar os resultados obtidos foi constatado em A. niger e decorreu de uma ação repressora das atividades de solubilização e da fosfatase ácida, por concentrações crescentes de fosfato (Nahas \& Assis, 1992).

A correlação significativa e positiva entre fosfato e acidez, em todos os ensaios, indica que para haver solubilização há necessidade da produção de ácidos (Tabela 1). Esse mecanismo tem sido amplamente relatado na literatura (Vassilev et al., 2006; Chuang et al., 2007). Ácidos orgânicos são liberados pelo fungo, como resultado da assimilação de carboidratos, e atuam na complexação do cátion do fosfato inorgânico para liberar fosfato solúvel (Whitelaw et al., 1999). Por sua importância prática, a secreção de ácido cítrico por A. niger é um dos mecanismos que mais têm sido estudados, e é reconhecido como intermediário do ciclo dos ácidos tricarboxílicos (Karaffa \& Kubicek, 2003). Embora o ácido cítrico tenha sido considerado como forte agente solubilizador (Vassilev et al., 2006), é provável que não tenha predominado em razão das condições 
adotadas no presente estudo. Roukas \& Harvey (1988) relataram que o ácido glucônico predominou em $\mathrm{pH}$ acima de 2,5, e o ácido cítrico em condições mais ácidas. Segundo Xu et al. (1989), concentrações de açúcar menores que $2,5 \%$, como as do presente trabalho, não induzem o processo metabólico da acidogênese. Também devem ser considerados: a diminuição do $\mathrm{pH}$ extracelular para aproximadamente 2 e concentrações limitantes de fosfato (Karaffa \& Kubicek, 2003). Estes requisitos podem explicar parcialmente os resultados obtidos.
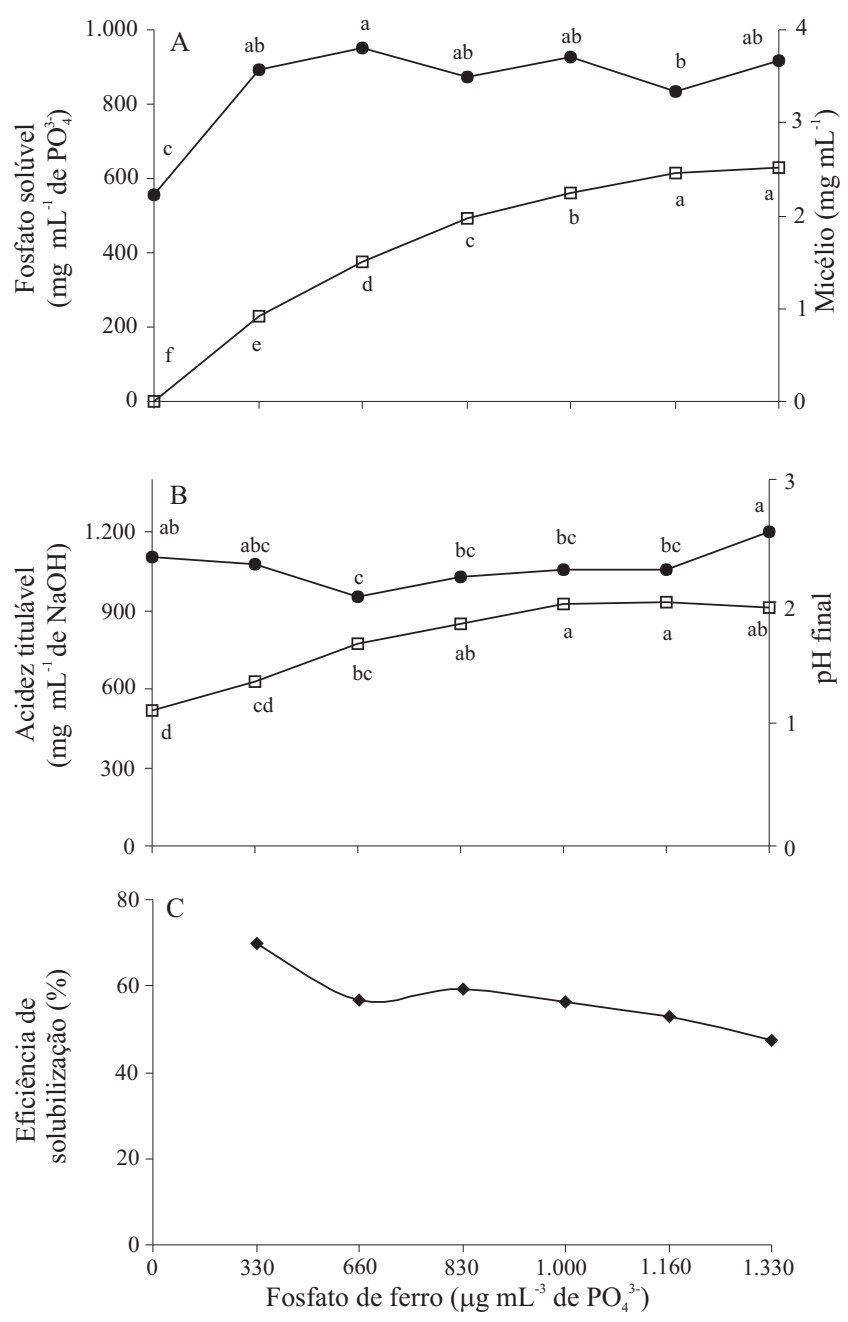

Figura 2. Eficiência de solubilização de concentrações crescentes do fosfato de ferro por Aspergillus niger. Médias com letras iguais não diferem entre si pelo teste de Tukey, a $5 \%$ de probabilidade. $\square$ : pH final e micélio.

\section{Conclusões}

1. Entre as fontes de carbono e de nitrogênio, manitol e ácido glutâmico, respectivamente, propiciam a maior eficiência de solubilização do fosfato de ferro.

2. A eficiência de solubilização do fosfato de ferro depende da fase de crescimento do fungo Aspergillus niger.

3. Concentrações de fosfato de ferro acima de $330 \mu \mathrm{g} \mathrm{mL}^{-1}$ de $\mathrm{PO}_{4}{ }^{3-}$ diminuem a eficiência de solubilização.

4. A produção de ácidos é o principal mecanismo utilizado pelo isolado de $A$. niger para a solubilização do fosfato de ferro.

\section{Agradecimentos}

À Fundação de Amparo à Pesquisa no Estado de São Paulo, por concessão de bolsa e pelo suporte financeiro; ao Conselho Nacional de Desenvolvimento Científico e Tecnológico, por concessão de bolsa.

\section{Referências}

AMES, B.N. Assay of inorganic phosphate and phosphatases. Methods of Enzymology, v.8, p.115-116, 1966.

BARROSO, C.B.; NAHAS, E. The status of soil phosphate fractions and the ability of fungi to dissolve hardly soluble phosphates. Applied Soil Ecology, v.29, p.73-83, 2005.

BIZUKOJC, M.; LEDAKOWICZ, S. The kinetics of simultaneous glucose and fructose uptake and product formation by Aspergillus niger in citric acid fermentation. Process Biochemistry, v.39, p.2261-2268, 2004

CHALOT, M.; BRUN, A.; FINLAY, R.D.; SÖDERSTRÖM, B. Metabolism of $\left[{ }^{14} \mathrm{C}\right]$ glutamate and $\left[{ }^{14} \mathrm{C}\right]$ glutamine by the ectomycorrhizal fungus Paxillus involutus. Microbiology, v.140, p.1641-1649, 1994.

CHUANG, C.C.; KUO, Y.L.; CHAO, C.C.; CHAO, W.L. Solubilization of inorganic phosphates and plant growth promotion by Aspergillus niger. Biology and Fertility of Soils, v.43, p.575-584, 2007.

GIBSON, B.R.; MITCHELL, D.T. Nutritional influences on the solubilization of metal phosphate by ericoid mycorrhizal fungi. Mycological Research, v.108, p.947-954, 2004.

ILLMER, P.; BARBATO, A.; SCHINNER, F. Solubilization of hardly-soluble $\mathrm{AlPO}_{4}$ with P-solubilizing microorganisms. Soil Biology and Biochemistry, v.27, p.265-270, 1995.

KARAFFA, L.; KUBICEK, C.P. Aspergillus niger citric acid accumulation: do we understand this well working black box? Applied Microbiology and Biotechnology, v.61, p.189-196, 2003. 
KOMANO, T. Formation of multiple forms of acid and alkaline phosphatases in relation to the culture age of Aspergillus niger. Plant and Cell Physiology, v.16, p.643-658, 1975.

KUMAR, S.; PUNEKAR, N.S.; SATYANARAYAN, V.; VENKATESH, K.V. Metabolic fate of glutamate and evaluation of flux through the 4-aminobutyrate (GABA) shunt in Aspergillus niger. Biotechnology and Bioengineering, v.67, p.575-584, 2000.

MULLEN, M.D. Phosphorus and other elements. In: SYLVIA, D.M.; HARTEL, P.G.; FUHRMANN, J.J.; ZUBERER, D.A. (Ed.). Principles and applications of soil microbiology. New Jersey: Prentice-Hall, 2005. p.463-488.

NAHAS, E.; ASSIS, L.C. Efeito da concentração de fosfato na solubilização de fluorapatita por Aspergillus niger. Revista de Microbiologia, v.23, p.37-42, 1992.

NAHAS, E.; CENTURION, J.F.; ASSIS, L.C. Microrganismos solubilizadores de fosfatos e produtores de fosfatases de vários solos. Revista Brasileira de Ciência do Solo, v.18, p.43-48, 1994.

NARSIAN, V.; PATEL, H.H. Aspergillus aculeatus as a rock phosphate solubilizer. Soil Biology and Biochemistry, v.32, p.559-565, 2000.

PAPAGIANNI, M.; FRANK, W.; MATTEY, M. Fate and role of ammonium ions during fermentation of citric acid by Aspergillus niger. Applied and Environmental Microbiology, v.71, p.7178-7186, 2005.

REYES, I.; BERNIER, L.; SIMARD, R.R.; ANTOUN, H. Effect of nitrogen source on the solubilization of different inorganic phosphates by an isolate of Penicillium rugulosum and two UV: induced mutants. FEMS Microbial Ecology, v.28, p.281-290, 1999.

ROUKAS, T. Citric and gluconic acid production from fig by Aspergillus niger using solid-state fermentation. Journal of Industrial Microbiology and Biotechnology, v.25, p.298-304, 2000.

ROUKAS, T.; HARVEY, L. The effect of $\mathrm{pH}$ on production of citric and gluconic acid from beet molasses using continuous culture. Biotechnology Letters, v.10, p.289-294, 1988.

RYMOWICZ, W.; LENART, D. Oxalic acid production by a mutant of Aspergillus niger at different $\mathrm{pH}$. Biotechnology Letters, v.25, p.955-958, 2003.
SILVA FILHO, G.N.; VIDOR, C. Solubilização de fosfatos por microrganismos na presença de fontes de carbono. Revista Brasileira de Ciência do Solo, v.24, p.311-319, 2000.

SON, H.J.; PARK, G.T.; CHA, M.S.; HEO, M.S. Solubilization of insoluble inorganic phosphates by a novel salt and $\mathrm{pH}$-tolerant Pantoea agglomerans R-42 isolated from soybean rhizosphere. Bioresource Technology, v.97, p.204-210, 2006.

SPERBER, J.I. Solution of apatite by soil microorganisms producing organic acids. Australian Journal of Agricultural Research, v.9, p.782-787, 1958.

VASSILEV, N.; FRANCO, I.; VASSILEVA, M.; AZCÓN, R. Improved plant growth with rock phosphate solubilized by Aspergillus niger grown on sugar-beet waste. Bioresource Technology, v.55, p.237-241, 1996.

VASSILEV, N.; MEDINA, A.; AZCÓN, R.; VASSILEVA, M. Microbial solubilization of rock phosphate on media containing agro-industrial wastes and effect of the resulting products on plant growth and P uptake. Plant and Soil, v.287, p.77-84, 2006.

WAKELIN, S.A.; WARREN, R.A.; HARVEY, P.R.; RYDER, M.H. Phosphate solubilization by Penicillium spp. closely associated with wheat roots. Biology and Fertility of Soils, v.40, p.36-43, 2004.

WHITELAW, M.A.; HARDEN, T.J.; HELYAR, K.R. Phosphate solubilisation in solution culture by the soil fungus Penicillium radicum. Soil Biology and Biochemistry, v.31, p.655-665, 1999.

XIN, C.; JIAN-JUN, T.; ZHI-GUO, F.; SHUI-JIN, H. Phosphatesolubilizing microbes in rhizosphere soils of 19 weeds in Southeastern China. Journal of Zhejiang University Science, v.3, p.355-361, 2002.

XU, D.B; MADRID, C.P.; RÖHR, M.; KUBICEK, C.P. The influence of type and concentration of the carbon source on production of citric acid by Aspergillus niger. Applied Microbiology and Biotechnology, v.30, p.553-558, 1989.

YUAN, Q.P.; WANG, J.D.; ZHANG, H.; QIAN, Z.M. Effect of temperature shift on production of xylanase by Aspergillus niger. Process Biochemistry, v.40, p.3255-3257, 2005.

ZAPATA, F.; AXMANN, H. ${ }^{32} \mathrm{P}$ isotopic techniques for evaluating the agronomic effectiveness of rock phosphate material. Nutrient Cycling in Agroecosystems, v.41, p.189-195, 1995. 